Supplement of Clim. Past, 13, 1037-1048, 2017

https://doi.org/10.5194/cp-13-1037-2017-supplement

(c) Author(s) 2017. This work is distributed under

the Creative Commons Attribution 3.0 License.

(c) (1)

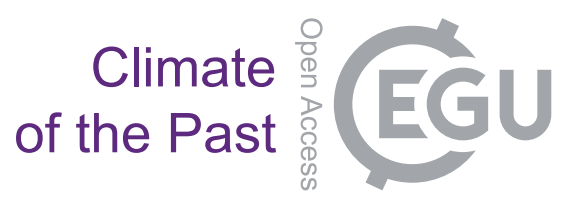

Supplement of

\title{
Atmospheric circulation and hydroclimate impacts of alternative warm- ing scenarios for the Eocene
}

\author{
Henrik Carlson and Rodrigo Caballero \\ Correspondence to: Henrik Carlson (henrik@misu.su.se)
}

The copyright of individual parts of the supplement might differ from the CC BY 3.0 License. 

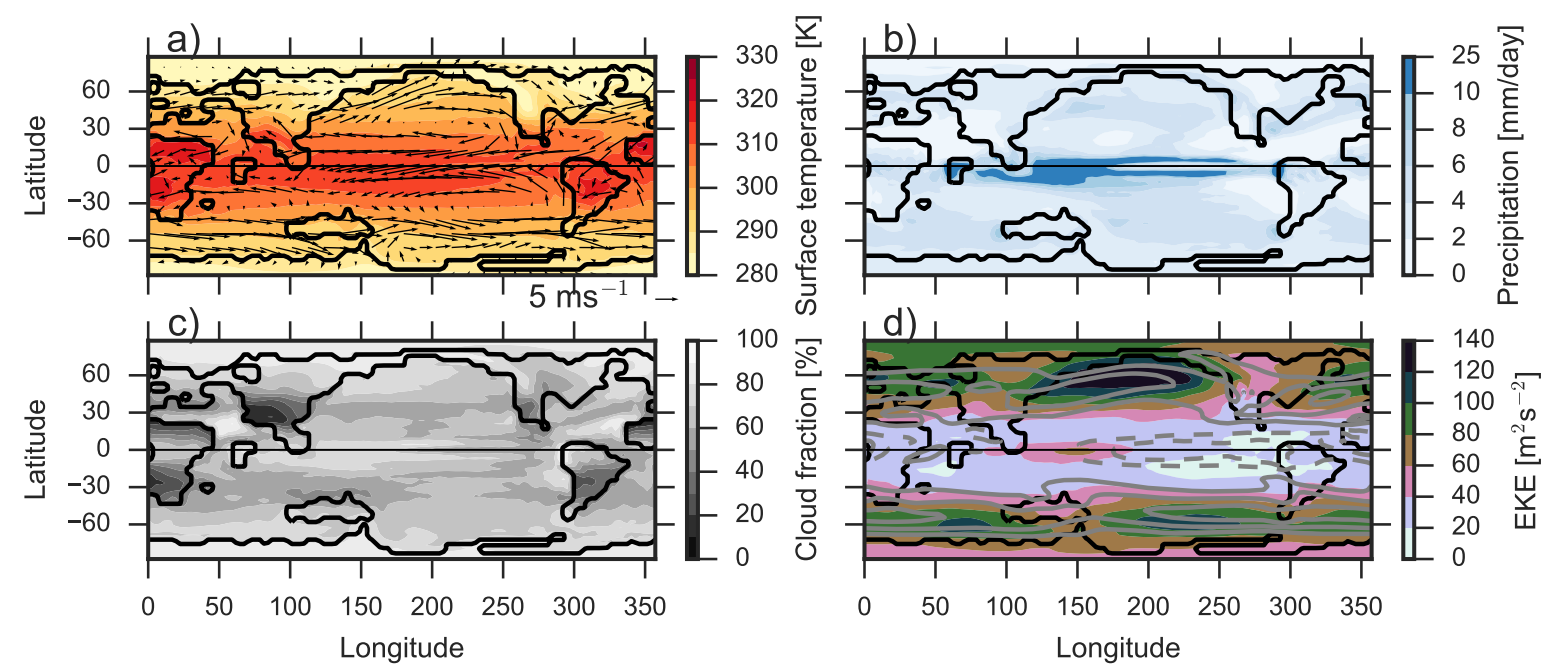

Figure S1. Annual-mean climatology in the LCTC case of (a) surface temperature (shading) and 900 hPa wind (arrows); (b) precipitation; (c) cloud fraction and (d) eddy kinetic energy (shading) and zonal wind at $700 \mathrm{hPa}$ (contours, c.i. $4 \mathrm{~ms}^{-1}$ in (d)). 